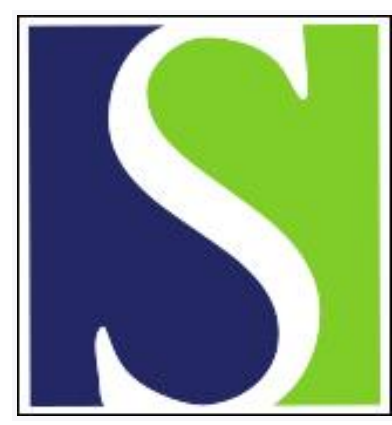

Scand J Work Environ Health 2003;29(5):325-327

https://doi.org/10.5271/sjweh.738

Issue date: Oct 2003

\title{
Can we cope with a shortage of time at work?
}

by Sallinen $M$

Affiliation: Finnish Institute of Occupational Health, Helsinki, Finland. Mikael.Sallinen@tt.fi

Refers to the following texts of the Journal: 2003;29(3):171-188 1998;24 suppl 3:43-48

The following article refers to this text: 2006;32(6):502-514

Key terms: coping; editorial; shortage of time; work

This article in PubMed: www.ncbi.nlm.nih.gov/pubmed/14584512 


\section{Can we cope with a shortage of time at work?}

In this year's third issue of the Scandinavian Journal of Work, Environment \& Health, van der Hulst summarized the results of 27 studies on the association between extended workhours and health (1). The review showed that long workhours are indeed associated with outcomes such as cardiovascular disease, disability retirement, and perceived poor health status, as well as with adverse changes in physiological functions and health-related behavior. Other studies have shown that long workhours are also associated with increased accident risk (2). In addition to long workhours, an intensification of work is a common experience. In the Third European Survey on Working Conditions 2000 (3), 56\% of all respondents reported working at high speed, and $60 \%$ had to contend with tight deadlines for at least one quarter of their time. According to the same survey, the intensification of work is closely associated with an increased prevalence of ill health, such as stress and musculoskeletal disorders. All in all, these results call for actions to help ease worktime shortages.

A review of current literature reveals that countermeasures for a lack of time at work have been examined less extensively than the relationship between long workhours and health. Despite the fact that it is not possible to list many scientifically proved results with respect to the countermeasures, it may be useful to present opinions on this topical issue to stimulate discussion and further research.

When a shortage of time at work is not due to understaffing, we have at least two options for coping with the problem. One avenue is to increase work efficiency.

A basic element of work efficiency is up-to-date competence, which is a hard demand in today's continually changing worklife. The role of learning methods has become essential in this situation. What is needed is the development and, in particular, the use of learning methods suitable for worklife. An example of such a method is what is called problem-based learning, even though there is no consensus on its superiority over traditional learning methods (4). With this method, we can alleviate cognitive overload in an information-rich environment by examining problems in-depth in groups so that we can apply and integrate our pieces of information. A similar idea of an active learner is used when teaching takes place at work. This method, which applies the principle of "learning by doing", is especially suitable for aging workers, as it allows the effective utilization of experience in the learning process (5).

In addition to acquiring up-to-date competence, we have to be able to use it effectively. Time management behavior is one way to meet this criterion. The main idea behind this measure is to organize work so well that the aim is continually focused and the working process is fluent. Time management behavior is usually divided into the following three parts: setting goals and priorities, using mechanisms of time management (eg, lists and schedules for tasks), and giving preference to organization (6). Ourrent evidence supports the hypothesis that the key factor between time manage ment behavior and its positive outcomes (eg, reduced job-induced tension, increased job satisfaction) is a perception of control over time (7). An encouraging finding is that commitment to time manage ment behavior, especially setting goals and priorities and giving preference to organization, can positively affect mental health and job satisfaction (7-9). A less encouraging observation, however, is that time management training, which is popular in worklife, does not seem to change time manage ment behavior to a great extent $(7,10)$. 
If and when limits are placed on the use of time in the horizontal direction, the amount of daily work could be increased through an intensification of the use of time in the vertical direction. Polychronicity, in contrast to monochronicity, means a preference for participation in many tasks at a time (11). It is known that people differ greatly in this respect, whereas the current work climate strongly favors polychronicity. Under these circumstances, many people are probably trying to work in a polychronic manner to an extent that exceeds their capacity. It is unlikely that this kind of overestimation of polychronicity increases work efficiency. Preferably, work efficiency could be enhanced if interindividual variation in chronicity is taken into account during the planning and organizing of work.

Although we could increase work efficiency significantly, it does not necessarily lead to a substantial decrease in the shortage of time. This paradox is, at least partially, based on the nature of efficiency itself. It is a quantity without an upper limit. Moreover, efficient workers are often rewarded with extra work, which keeps the shortage of time constant. This argument does not make competence and time management behavior worthless, but it calls for other actions to complete the repertoire needed to get results. A critical question in addition to work efficiency is "How should limits be set at work?" This question has been made especially challenging by the development of the past five or six decades, during which the focus of work demands has shifted from routine-type physical work towards mental work, which requires creative thinking. In addition, new information and communication technology has made it possible to work anywhere anytime, and this change has obscured the border between work and spare time.

Organizational measures are probably needed when limits are set for work, and they should be applied to both workhours and the amount of work. Measures such as registration of and controlling for workhours and the existence of a foreman who knows the current work situation of his or her employees may sound Victorian. On the other hand, the function of these measures can vary in different times. In industrial societies, they are mainly used to insure that employees do not work too little, while, in information societies, they can be used to see that employees do not work too much. Because the ability to evaluate the time and energy needed to accomplish a worktask varies from person to person, it is well grounded to use these measures in a more flexible way than has been done in industrial societies.

The manner in which limits are developed for work and introduced in an organization is likely to determine to a great extent how feasible the limits are.

In addition to the employer and the employees, the shown associations between the shortage of time at work and ill health emphasize the role of occupational health care in this matter. For example, the occupational health care legislation of Finland makes the employer responsible for organizing occupational health care to prevent work-related health risks and to promote safety and health at work. Means for carrying out this assignment are, accordingly, the evaluation of workload and work arrangements, as well as the introduction of proposals to improve the "healthiness" of work and compatibility between work demands and employee's resources. To be able to estimate the sufficiency of time allocated for the assigned (or chosen) tasks, occupational health care needs many kinds of information (eg, data on the amount of overtime work, the prevalence of projects accomplished in time, and stress stemming from deadlines that are too tight). This information also creates a basis for occupational health care professionals' attempts to improve the allocation of time to various worktasks.

From the viewpoint of preventive actions, studies on human psychophysiological limits in various work conditions and, in particular, studies on feasible solutions, which could help to use our psychophysiological resources in an optimal way, would be valuable. This line of research includes questions on optimal learning methods, the optimal quantity and quality of information, the recommendable organization of worktasks from the viewpoint of cognitive functions, guidelines for a ratio between work and rest, and possibilities to arrange workhours in healthy and mutually flexible ways. As long as 
these results are lacking or they are poorly introduced to occupational health care, the actions of occupational health professionals lean too heavily on common sense, which is often fine but not as influential as scientific evidence.

In the end, our values determine the strategy that can best alleviate the shortage of time at work. In a society prioritizing economic values, the significance of reasonable time budgets could be demonstrated by showing their positive impact on productivity in the long run. This evidence would also stimulate research on the effectiveness of various countermeasures for the shortage of time at work.

\section{References}

1. van der Hulst M. Long workhours and health. Scand J Work Environ Health 2003;29:171-88.

2. Hänecke K, Tiedemann S, Nachreiner F, Grzech-Šukalo H. Accident risk as a function of hour at work and time of day as determined from accident data and exposure models for the German working population. Scand J Work Environ Health 1998;24 Suppl 3:43-8.

3. Pascal P, Damien M. Third European survey on working conditions 2000. Luxembourg: European Foundation for the Improvement of Living and Working Conditions; 2001.

4. Colliver JA. Effectiveness of problem-based learning curricula: research and theory. Acad Med. 2000;75:259-66.

5. Ilmarinen J. Ageing workers in the European Union-status and promotion of work ability, employability and employment. Helsinki: Finnish Institute of Occupational Health, Ministry of Social Affairs and Health, and Ministry of Labor; 1999.

6. Macan T, Shahani C, Dipboye RL, Phillips AP. College students time management: correlations with academic performance and stress. J Educ Psychol 1990;82:760-8.

7. Macan TH. Time management: test of a process model. J Appl Psychol 1994;79:381-91.

8. Jex SM, Elacqua TC. Time management as a moderator of relations between stressors and employee strain. Work Stress 1999;13:182-91.

9. Lang D. Preventing short-term strain through time-management coping. Work Stress 1992;2:169-76.

10. Macman TH. Time management training: effects on time behaviors, attitudes and job performance. J Psychol 1996;130:22936.

11. Bluedorn AC, Kaufman CF, Lane PM. How many things do you like to do at once: an introduction to monochronic and polychronic time. Acad Manage Executive 1992;6:17-26.

Mikael Sallinen, $\mathrm{PhD}$

Fnnish Institute of Occupational Health

Helsinki, Fnland

Mikael.Sallinen@ttl.fi 


\section{Scandinavian Journal of Work, Environment \& Health}

The Scandinavian Journal of Work, Environment \& Health is an international scientific periodical which began publication in 1975. The Journal appears 6 times a year, at the end of February, April, June, August, October, and December. In addition 1 to 3 self-financed supplements on specific topics are generally published annually.

The circulation of the Journal is worldwide. By the end of 2002, the total distribution was about 1100 copies to approximately 45 countries on 5 continents. Most of the subscriptions came from the United States (184), The Netherlands (89), Italy (68), Canada (51), Finland (51), Great Britain (50), Germany (48), Norway (48), Sweden (43), Spain (33), Japan (31), Australia (28), Denmark (27), and France (27).

The Journal is open to all authors without regard to nationality. In 2002, the number of manuscripts submitted for publication in a regular issue was 192. In volume 28 , the first author of the 83 published articles (supplements included) was from Finland (25), Sweden (14), The Netherlands (10), the United States (9), Denmark (4), the United Kingdom (3), France (3), Germany (3), Norway (2), Canada (2), Spain (2), Switzerland (2), Japan (1), Korea (1), Argentina (1), and Turkey (1).

The acceptance rate of the 192 articles submitted in 2002 was $23 \%$ by the end of March 2003; at that time the decision was still pending for 28 of the manuscripts.

In a peer-review process, 1 to 4 referees independently evaluate the scientific quality of the submitted manuscripts. The Journal uses a double-blind peerreview system.

The elapsed time from submission to publication for the articles published in 2002 averaged 9 months. A decision of acceptance of a manuscript was reached in 1 to 3 months (average 7 weeks).

The Journal is indexed or abstracted in Current Contents, the Science Citation Index, Biological Abstracts, Excerpta Medica, CISDOCE HSELINE, TZXLIRE, NIOSHTIC, etc.

For the latest year available, 2002, the impact factor of the Journal was 1.848 . 